\title{
Preoperative Immune Response is Associated with Perioperative Transfusion Requirements in Glioma Surgery
}

\author{
Qi Zhang ${ }^{1}$, Huahui $W^{2}$, Jingjun Zhang ${ }^{1}$, Qi Qi ${ }^{1}$, Wei Zhang ${ }^{\circledR}$, Rong Xia ${ }^{\circledR}$ \\ 1. Department of Blood Transfusion, Huashan Hospital, Fudan University, Shanghai, China \\ 2. Harbin Hospital of Traditional Chinese Medicine, Harbin, Heilongjiang, China \\ 3. Department of Medical Imaging, Renji Hospital, Medical School of Jiaotong University, Shanghai, China
}

$\square$ Corresponding authors: Wei Zhang: Department of Medical Imaging, Renji Hospital, Medical School of Jiaotong University. E-Mail: zhangwei975@163.com; Tel/Fax: +86-21-56952231. Rong Xia: Department of Blood Transfusion, Huashan Hospital, Fudan University. E-Mail: xiarongcn@163.com; Tel/Fax: $+86-21-52888330$

(c) Ivyspring International Publisher. This is an open access article distributed under the terms of the Creative Commons Attribution (CC BY-NC) license (https://creativecommons.org/licenses/by-nc/4.0/). See http://ivyspring.com/terms for full terms and conditions.

Received: 2018.08.02; Accepted: 2019.05.05; Published: 2019.06.09

\begin{abstract}
Immunosuppression induced by transfusion causes postoperative adverse events including poor prognosis in cancer, but data on influence of the immune response on blood transfusion requirements during perioperative period are limited. The aim of this study was to investigate whether the preoperative immune response is associated with perioperative blood cell transfusion in a glioma surgical patient population. The authors identified 321 cases of surgery for treatment of glioma. Patient variables, preoperative laboratory variables (hemoglobin, platelet count, activated partial thromboplastin time, prothrombin time, hematocrit, red and white blood cell count), and transfusions were registered. Plasma concentration of Th-associated cytokines was measured by flow cytometry. Multivariable regression analysis and receiver operating characteristic curve were undertaken to identify predictors of transfusion. Of 321 patients, $157(48.90 \%)$ received red blood cells transfusion. The mean age is significantly higher in transfusion group compared to no transfusion group, while postoperative hospital stay, preoperative hemoglobin, prothrombin time, activated partial thromboplastin time, platelet count, red and white blood cell count and hematocrit of patients did not differ significantly between the two groups. No significant differences of IL-2, -4, -6, - 10 and INF- $\gamma$ concentration were observed between transfusion and no transfusion group. The concentration of TNF and IL-17A was significantly lower in transfusion patients than in the no transfusion subjects. Low plasma TNF and IL-17A levels predicted high perioperative transfusion rate, the combination of them enlarged the prognostic accuracy of testing. Our study demonstrates that the preoperative immune response influences transfusion requirements, and TNF and IL-17 are important predictive risk factors for perioperative use of blood components in glioma patients.
\end{abstract}

Key words: immune response, transfusion requirements, cytokines, glioma surgery, preoperation

\section{Introduction}

Brain glioma is the common primary intracranial tumor, characterized by dismal prognosis and frequent recurrence [1]. The treatment strategies presently available for malignant glioma include removing the local lesion by surgery. Due to possibility of severe hemorrhage in perioperative, patients in glioma surgery often require blood transfusion. As we all know transfusion is accompanied with a number of risks, including transfusion-transmitted diseases, transfusion-related lung injury, and so on $[2,3]$. More importantly, some studies have shown clearly that immunosuppression induced by transfusion causes postoperative adverse events, especially poor prognosis in cancer patients [4-8]. So minimize the possibility of blood transfusion may be important to improve prognosis and decrease cancer recurrence for glioma patients. Besides autologous blood transfusion another important way to minimize the need to transfusions might be confirm the influence factor of bleeding or transfusion requirements then to treatment.

Until now, the investigation of perioperative risk factors associated with bleeding and transfusion is limited, mostly of them has been based largely on a 
few general markers of hemostasis (activated partial thromboplastin time (aPTT), prothrombin time (PT), platelet count) $[9,10]$, but these variables have low ability to identify patients with increased transfusion rates. On the other hand, correlations between immune modulations and coagulation and bleeding have been reported $[11,12]$. Plasma cytokines released by ultrafiltration during perioperation may reduce postoperative blood loss and transfusion requirements, and it has also been identified that a low preoperative Th1 immune response was associated with a higher blood transfusion rate in cardiac surgery [13].

According to a well-known relationship between immune modulation and coagulation, the aim of this study was to investigate the relationship between preoperative immune response, as well as laboratory variables, and perioperative blood transfusion in a glioma surgical patient population.

\section{Materials and methods}

\subsection{Patients}

A total of 321 glioma patients were enrolled in this study at the Department of Neurosurgery, Huashan Hospital in Shanghai, China. Patient eligibility criteria were as follows: (1) with histologically confirmed primary glioma, (2) received surgical resection, (3) availability of complete clinical data and (4) no history of other synchronous malignancy. The study was approved by the Ethic Committee of Fudan University and informed consents were obtained from all participants. All experimental procedures were performed according to the Helsinki Declaration. Patients' clinical data were obtained by medical record review.

\subsection{Laboratory Data and Cytokine assay}

On the day before surgery, the patients' blood samples were collected for routine laboratory analysis including $\mathrm{Hb}, \mathrm{PT}$, aPTT, platelet count, RBC count, WBC count and hematocrit. After analysis, plasma samples were separated by density gradient centrifugation, and aliquots were stored at $-80^{\circ} \mathrm{C}$ until further processing for the simultaneous quantification of cytokines.

Cytometric Bead Array Human $T$ helper1(Th1)/Th2/Th17 Cytokine Kit (BD Bioscience San Jose, CA) was used to measure plasma levels of interleukin (IL)-2, -4, -6, -10, tumor necrosis factor (TNF), interferon (INF)- $\gamma$ and IL-17A (Table 1), data were acquired on a BD FACSCanto II flow cytometer. Both assays were performed according to the manufacturer's instructions and the results are reported in $\mathrm{pg} / \mathrm{ml}$.

\subsection{Perioperative blood transfusion}

Perioperative blood transfusion was defined as at least 1 unit of allogeneic red blood cell transfusion either during operation or within 24 hours after operation. Blood transfusion during operation was decided according to the institution's clinical protocol [14] (red blood cell transfusions were given when blood hemoglobin level decreased to below $70 \mathrm{~g} / \mathrm{L}$ ). The attending anesthesiologist, who always had the final decision regarding transfusions, was not aware of the preoperative cytokines concentration. No patients had predeposit autologous blood transfusion.

\subsection{Statistical analysis}

Continuous variables were expressed as the mean values \pm standard deviation (SD) and compared with Student $t$ test or Mann-Whitney U-test. Categoric variables were tested with Pearson chi-square test. Variables with a $p$ value of 0.10 or less were retained for multivariate analyses to assess whether cytokines expression was independently associated with blood transfusion. To determine any thresholds of continuous variables predictive of blood transfusion, a receiver operating characteristic (ROC) curve was constructed. SPSS Statistics v 19.0(SPSS Inc., Chicago, Illinois) were used for all statistical calculations. $\mathrm{P}<0.05$ was considered to be statistically significant.

Table 1. Selected cytokines and their related pathways activity on tumours [15-19]

\begin{tabular}{|c|c|c|c|}
\hline Cytokines & Immune pathway & $\begin{array}{l}\text { Contributes to anti(-) } \\
\text { or pro(+) inflammatory } \\
\text { phenotype }\end{array}$ & $\begin{array}{l}\text { Activity on } \\
\text { tumours }\end{array}$ \\
\hline IL-2 & $\begin{array}{l}\text { Promotes Th1 } \\
\text { differentiation and inhibits } \\
\text { Th17 differentiation }\end{array}$ & + & Antitumoral \\
\hline IL-4 & $\begin{array}{l}\text { Promotes of Th2 } \\
\text { differentiation }\end{array}$ & - & Pro-tumoral \\
\hline IL-6 & $\begin{array}{l}\text { Promotes } \\
\text { Th17differentiation and } \\
\text { inhibits Treg differentiation }\end{array}$ & + & Pro-tumoral \\
\hline IL-10 & $\begin{array}{l}\text { Anti-inflammatory cytokine } \\
\text { produced by many T cell } \\
\text { subtypes and some } \\
\text { macrophages }\end{array}$ & - & Pro-tumoral \\
\hline TNF & $\begin{array}{l}\text { Common end product of } \\
\text { many innate and adaptive } \\
\text { immune pathways }\end{array}$ & + & Antitumoral \\
\hline INF- $\gamma$ & Th1 effector cytokine & + & Antitumoral \\
\hline IL-17A & $\begin{array}{l}\text { Cytokine produced by Th17 } \\
\text { cell }\end{array}$ & + & $\begin{array}{l}\text { Antitumoral/P } \\
\text { ro-tumoral }\end{array}$ \\
\hline
\end{tabular}

\section{Results}

\subsection{General Parameters}

A total of 321 patients (mean age $53.31 \pm 10.09$, range 29 to $70,46.42 \%$ female, Table 2) who underwent glioma surgery were included in the study. Of $321,157(48.90 \%)$ of the patients (range 39 to $70,45.86 \%$ female) received red blood cells transfusion (3.4 \pm 1.19 , range 2 to 6 units). None of the 
patients received platelet transfusion. The mean age in transfusion group was significantly higher compared to no transfusion group $(56.96 \pm 8.34$ vs $47.12 \pm 10.36, \mathrm{P}=0.02)$. Among the total patients 236 were diagnosed with low-grade glioma (WHO grade I or II) including 121 no transfusion and 115 transfusion patients, whereas 85 were diagnosed with high-grade glioma (WHO grade III or IV) including 43 no transfusion and 42 transfusion patients. The mean hospital stay of patients after operation was12.09 \pm 5.30 days, including $11.19 \pm 4.56$ days for no transfusion group and $13.04 \pm 6.36$ days for transfusion group.

Table 2. Clinical Characteristic of Patients

\begin{tabular}{ll}
\hline Variables & Whole Sample (N=321) \\
\hline Age(year) & $53.31 \pm 10.09$ \\
Gender & \\
Female (\%) & $46.42 \%$ \\
Male (\%) & $53.58 \%$ \\
Location & \\
Cerebellum & $4.36 \%$ \\
Diencephalon & $10.59 \%$ \\
Telencephalon & $71.96 \%$ \\
Ventricle & $13.09 \%$ \\
WHO Grade & \\
I-II & $73.52 \%$ \\
III-IV & $26.48 \%$ \\
Surgery & \\
Gross total resection & $85.98 \%$ \\
Near total resection & $14.12 \%$ \\
Hemoglobin (g/L) & $127.65 \pm 14.52$ \\
Prothrombin time (INR) & $0.94 \pm 0.08$ \\
aPTT (s) & $26.79 \pm 4.99$ \\
Platelet count ( $\left.10^{9} / \mathrm{L}\right)$ & $166.61 \pm 58.09$ \\
RBC(1012/L) & $4.51 \pm 0.35$ \\
Hematocrit $(\%)$ & $36.94 \pm 4.05$ \\
WBC count ( $\left.10^{9} / \mathrm{L}\right)$ & $11.57 \pm 7.29$ \\
Postoperative hospital stay (day) & $12.09 \pm 5.30$ \\
\hline aPTT indicates activated partial thromboplastin time; INR, international \\
normalized ratio; RBC, red blood cell; WBC, white blood cell. \\
\hline
\end{tabular}

\subsection{Routine Laboratory Analyses}

To further analyze risk factors for perioperative transfusion, we investigated routine laboratory maker of anemia and hemostasis. Preoperative Hb, PT, aPTT, platelet count, RBC count, WBC count and hematocrit were within the normal range for all patients before surgery (Table 3) and these routine laboratory variables did not differ significantly between the two groups.

\subsection{Transfusion and Cytokine secretion profile}

To identify the relationship between preoperative immune response and blood requirement in perioperative, plasma levels of the Th1/Th2/Th17 cytokines of glioma patients were tested and results showed that plasma levels of TNF $(\mathrm{P}<0.01)$ and IL-17A $(\mathrm{P}<0.01)$ were significantly lower in transfusion patients than in the no transfusion subjects. No significant difference was observed between the studied groups for IL-2, $-4,-6,-10$ and INF- $\gamma$ cytokines (Figure 1).

Table 3. Characteristics of patients requiring perioperative blood transfusion following scheduled glioma surgery

\begin{tabular}{llll}
\hline Variables & $\begin{array}{l}\text { Non-Transfusion } \\
(\mathrm{N}=164)\end{array}$ & $\begin{array}{l}\text { Transfusion } \\
(\mathrm{N}=157)\end{array}$ & P value \\
\hline Age(year) & $47.12 \pm 10.36$ & $56.96 \pm 8.34$ & 0.02 \\
Gender & & & 0.10 \\
Female (\%) & $46.95 \%$ & $45.86 \%$ & \\
Male (\%) & $53.05 \%$ & $54.14 \%$ & \\
Location & & & 0.15 \\
Cerebellum & $5.49 \%$ & $3.18 \%$ & \\
Diencephalon & $11.59 \%$ & $9.55 \%$ & \\
Telencephalon & $71.34 \%$ & $72.61 \%$ & \\
Ventricle & $11.59 \%$ & $14.65 \%$ & \\
WHO Grade & & & 0.54 \\
I-II & $73.78 \%$ & $73.25 \%$ & \\
III-IV & $26.22 \%$ & $26.75 \%$ & \\
Surgery & & & 0.37 \\
Gross total resection & $88.41 \%$ & $83.44 \%$ & \\
Near total resection & $11.59 \%$ & $16.56 \%$ & \\
Hemoglobin (g/L) & $132.4 \pm 15.24$ & $122.79 \pm 12.03$ & 0.21 \\
Prothrombin time (INR) & $0.91 \pm 0.08$ & $0.95 \pm 0.07$ & 0.47 \\
aPTT (s) & $24.47 \pm 5.18$ & $27.68 \pm 4.34$ & 0.28 \\
Platelet count (10 $/ \mathrm{L})$ & $167.67 \pm 49.40$ & $165.41 \pm 65.29$ & 0.79 \\
RBC(1012/L) & $4.6 \pm 0.70$ & $4.41 \pm 0.85$ & 0.06 \\
Hematocrit $\%$ ) & $37.45 \pm 3.31$ & $34.56 \pm 4.23$ & 0.10 \\
WBC count (10 $/ \mathrm{L})$ & $13.24 \pm 5.36$ & $9.56 \pm 5.69$ & 0.05 \\
Postoperative hospital stay (day) & $11.19 \pm 4.56$ & $13.04 \pm 6.36$ & 0.21 \\
\hline
\end{tabular}

\subsection{Independent predictive factors for transfusion requirement}

On univariable analysis, older patients and those with lower pre-operative plasma TNF and IL-17A were more likely to undergo blood transfusion. In order to further confirm the relationship between variables and perioperative blood transfusion, we choose all the variables with a $p$ value less than 0.1 were included in the multivariate analysis. Two variables of levels of TNF and IL-17A remained significant in this model, but age was no longer significant on multivariable analysis (Table 4).

Table 4. Multivariable logistic regression analysis of variables related to perioperative transfusion

\begin{tabular}{llll}
\hline Variables & Odds Ratio & $95 \% \mathrm{Cl}$ & P value \\
\hline Age & 1.01 & $0.90-1.11$ & 0.07 \\
RBC & 1.12 & $0.03-0.07$ & 0.58 \\
Hematocrit & 1.08 & $0.68-1.9$ & 0.80 \\
TNF & 3.47 & $1.05-7.22$ & 0.03 \\
IL-17A & 0.99 & $1.2-1.56$ & 0.03 \\
\hline
\end{tabular}

To further evaluate the possibility of clinical application of plasma TNF and IL-17A as a marker for predicting perioperative transfusion, a ROC curve was constructed. Perioperative TNF and IL-17A ROC curve had an area under the curve of 0.70 and 0.75 . Balancing sensitivity and specificity, the optimum threshold that predicted transfusion were 1.58 for 

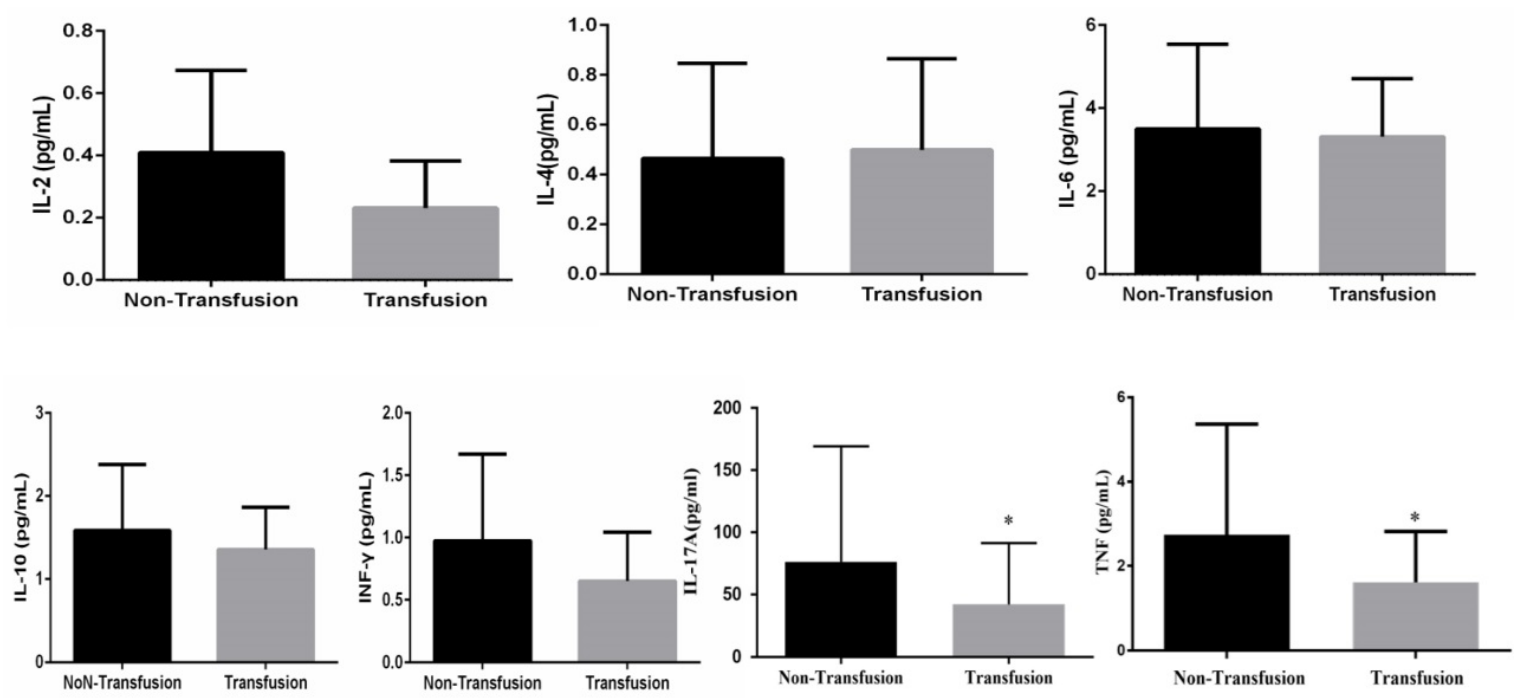

Figure 1. Preoperative Th1/Th2/Th17 cytokines (IL-2, -4, -6, -10, TNF, INF-Y and IL-17A) expression in plasma (*P<0.05, difference between two groups of patients).

TNF (sensitivity $=76.70 \%$, specificity $=73.30 \%$ ) and 38.73 for IL-17A (sensitivity $=72.30 \%$, specificity $=$ $69.96 \%$ ). Our results provided evidence that plasma TNF and IL-17A levels may be useful as a marker for predicting perioperative transfusion.

\subsection{Association of cytokine levels with transfusion requirement}

To validate the value of TNF in predicting transfusion requirement, the 321 patients were divided into two groups: the TNF $\leq 1.58 \mathrm{pg} / \mathrm{ml}$ group $(\mathrm{n}=173)$ and the TNF $>1.58 \mathrm{pg} / \mathrm{ml}$ group $(\mathrm{n}=148)$. The data showed that the transfusion rates were significantly higher in the TNF $\leq 1.58 \mathrm{pg} / \mathrm{ml}$ group than in the TNF $>1.58 \mathrm{pg} / \mathrm{ml}$ group $(70.52 \%$ vs $23.65 \%, P<0.01$ ) (Figure $2 \mathrm{~A}$ ). On the other hand, patients were also divided into two groups: the IL-17A $\leq 38.73 \mathrm{pg} / \mathrm{ml}$ group $(\mathrm{n}=151)$ and the IL-17A > $38.73 \mathrm{pg} / \mathrm{ml}$ group $(\mathrm{n}=170)$. The data showed that the transfusion rates were significantly higher in the IL-17A $\leq 38.73 \mathrm{pg} / \mathrm{ml}$ group than in the IL-17A > $38.73 \mathrm{pg} / \mathrm{ml}$ group $(68.87 \%$ vs $31.18 \%, P<0.01)$ (Figure 2B).

Finally, we decided to propose a novel predictive marker based on a combined analysis of plasma TNF and IL-17A. Patients were divided into three groups: Group1: both TNF $\leq 1.58 \mathrm{pg} / \mathrm{ml}$ and IL-17A $\leq 38.73 \mathrm{pg} / \mathrm{ml}$; Group2: both TNF $\leq 1.58$ $\mathrm{pg} / \mathrm{ml}$ and IL-17A $>38.73 \mathrm{pg} / \mathrm{ml}$ or both TNF $>1.58$ $\mathrm{pg} / \mathrm{ml}$ and IL-17A $\leq 38.73 \mathrm{pg} / \mathrm{ml}$; Group3: both TNF $>1.58 \mathrm{pg} / \mathrm{ml}$ and NLR IL-17A > $38.73 \mathrm{pg} / \mathrm{ml}$. The transfusion rates were markedly higher in group 1 than in group 2 and group $3(83.65 \%, 43.10 \%$ vs $19.80 \%, P<0.001$ ) (Figure 2 C). Our results provided evidence that plasma TNF and IL-17A levels may be useful as a marker for predicting perioperative transfusion, the combination of them enlarged the prognostic accuracy of testing.

\section{Discussion}

In this study, the authors prospectively investigated the influence of preoperative Th1/Th2/ Th17 immune response on transfusion need in 321 consecutive patients undergoing scheduled glioma surgery. After analysis of immunological factors and laboratory risk factors for blood transfusion, results showed that patients with a lower preoperative Th1 and Th17 response, as assessed by lower TNF and IL17A level, had a significantly higher risk for receiving red blood cells. Hence, these results unveiled a new aspect of relationship between transfusion and immune function, and not only preoperative anemia and hemostasis markers but also preoperative immune response may influence perioperative blood transfusion need in glioma surgical patients.

In general, preoperative anemia and hemostasis factors determine the risk of perioperative blood transfusion. Anemia and impaired hemostasis are associated with increased rates of transfusion. In this study, there was no difference in $\mathrm{Hb}, \mathrm{PT}$, aPTT, and platelet count between transfusion and no transfusion group. So, there must be some other factors influence blood transfusion requirements in glioma surgery.Intracranial tumors including glioma are invariably infiltrated with various types of immune cells, although the blood-brain barrier maintains an immune-privileged status of the brain under steady state [20, 21]. The Th1and Th2 cells act in an antagonistic fashion, the Th1 helper population is generally pro-inflammatory and stimulates a cell-mediated response. Th2 cells stimulate the 


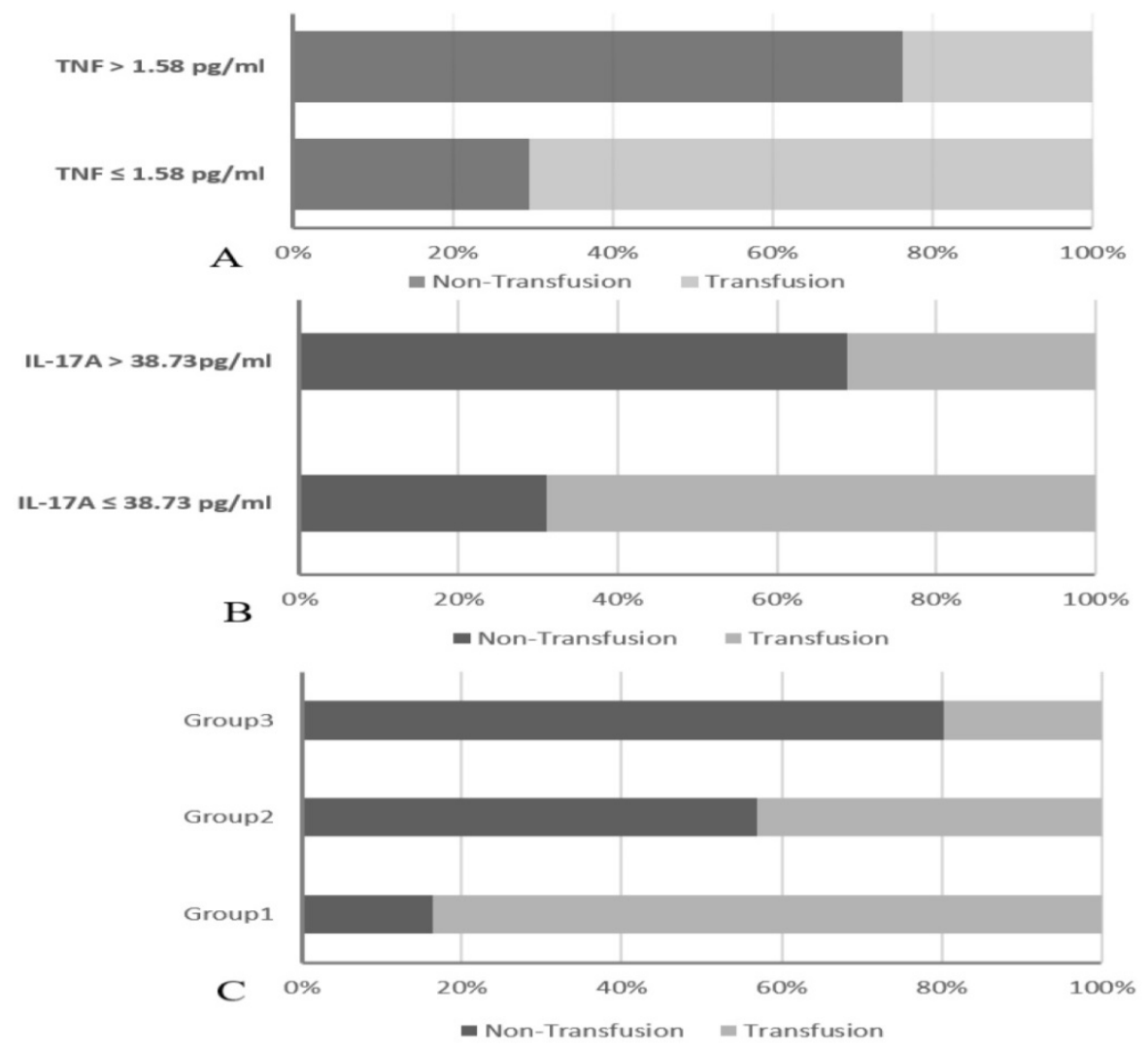

Figure 2. The combination of TNF and IL-17A was found to enhance prognostic accuracy for perioperative transfusion requirements.

humoral immune response [20, 21], the balance between Th1 and Th2 cytokines is thought to be an important factor in terms of tumor progression and prognosis. The Th17 cell is involved in much autoimmune and infectious pathology. It is also associated with the tumorigenesis process and poor prognosis of certain tumors [22]. Adoptively transferred Th17 cells also impact the immunological microenvironment of the glima [22, 23]. In recent times, a growing number of studies have showed that red blood cell transfusion has been link to immunosuppressed phenotype in cancer patients via inducing a shift of Th1/Th2 balance toward Th2 dominance, which leads to poor prognosis including glioma [21, 24, 25], but limit studies focus on immune status before transfused.

Our data showed a reduced preoperative Th1 and Th17 cytokines level may predispose to greater red blood cell consumption, and the underlying molecular mechanism may be related with inflammation-induced thrombosis. Immune response, including inflammatory (Th1) and anti-inflammatory (Th2) cytokine responses, has been reported to be relating to coagulation and bleeding. Increasing evidence has shown that inflammatory cytokines, such as TNF, have a profound effect on endothelial cell injury via regulating endothelial phenotypes, modulating the coagulant system. In this regard, Santiago and his colleagues have also identified that patients with a lower preoperative Th1 response, as assessed by a lower percentage of TNF producing CD4+T cells, had a significantly higher risk for receiving red blood cells units [13]. During inflammation, TNF is in part responsible for regulation of thrombomodulin, protein $\mathrm{C}$ and tissue factor expression. Thrombomodulin, as a cofactor for thrombin, expresses on the endothelial surface after trauma. The thrombin-thrombomodulin complex inhibits coagulation and activates the fibrinolytic pathway, favoring bleeding via activating protein $\mathrm{C}$. Therefore, low preoperative counts of TNF may result in upregulation of activated protein $\mathrm{C}$ expression and downregulation of tissue factor expression, which may lead to increased perioperative bleeding in predisposed patients [13]. IL-17A is the signature cytokine produced by TH17 cells and has recently taken center stage in pathophysiology of autoimmunity. This cytokine plays a pivotal role in inflammation and tissue injury and its dysregulation may cause autoimmune diseases [23, 26]. IL-17A can induce the expression of pro-inflammatory genes and activate coagulation and vascular remodeling [27]. Incubation of platelets with IL17Apromotes ADP-induced CD62P expression and fibrinogen binding, and facilitates their adhesion to damaged endothelium as well as to other circulating leukocytes ultimately leading to thrombus formation [26]. Moreover, IL17A promotes angiogenesis, which contributes to later stages of thrombus organization [28].

Therefore, TNF and IL17A influence transfusion need because of their linking with coagulation system or platelet aggregation. Additionally, a potential TNF-a/IL-17 synergism interaction of the two factors has also been shown to play a role in a variety of physiological and pathological processes [29]. IL-17 specifically when combined with TNF has major pro-coagulant and pro-thrombotic effects on vessels. IL-17/TNF regulated key molecules genes in psoriasis pathogenesis, IL-17 and TNF act in a synergistic manner to induce a distinct pattern of endothelial 
activation that sustains and enhances neutrophil influx to sites of inflammation [30]. In our results, fortunately, IL-17 and TNF were synergistic factors for transfusion need, and the synergism was found between two variables.

Not surprisingly, immunity function of the old declined as growing older, the present results also showed average age of patients with glioma in transfusion group was older than that of patients in no transfusion group, and elderly patients with glioma had a higher risk of perioperative blood transfusion. These results are in agreement with our previous work, we have analyzed perioperative blood transfusion of brain tumor surgery, we found that the number of cancer patients with transfusion increases in an age-dependent manner [31].

There are potential limitations to this study. First, it is a retrospective and single-institution study. Thus, our findings need to be further validated with a well-designed, prospective study with larger number of patients. Second, we only performed association analyses between blood cell transfusion need and immunological parameters of glioma patients. The underlying mechanisms through which immune cytokines affect the blood loss have not been clearly elucidated and further investigation is needed to corroborate these findings.

In conclusion, our study demonstrates that age, TNF and IL-17 are important predictive risk factors for perioperative use of red blood cell in glioma, and immune response-related variables, in combination with other patient and perioperative variables, may improve the predictive capacity for transfusion in glioma patients. This article provides evidence of low levels of immunity resulting in transfusions, and more evidence has already shown that transfusions can lead to immunosuppression. There may be a positive feedback between blood transfusions and reduced immune response, and future research should be performed for a better comprehension of immune balance and transfusion.

\section{Acknowledgements}

The present study is supported by National Natural Science Foundation of China (81570166 and 81670173) and Public Health Leading Academic Discipline Project supported by Shanghai Municipal Commission of Health and Familly Planning (No.15GWZK0501).

\section{Author Contributions}

Study conception and design: Qi Zhang, Rong Xia, Wei Zhang.

Acquisition of data: Jingjun Zhang, Qi Qi, Qi Zhang.
Analysis and interpretation of data: Huahui Wu. Drafting of manuscript: Huahui Wu, Qi Zhang. Critical revision: Wei Zhang, Rong Xia.

\section{Competing Interests}

The authors have declared that no competing interest exists.

\section{References}

[1] Liu Q, Liao F, Wu H, Cai T, Yang L. Upregulation of miR-132 expression in glioma and its clinical significance. Tumor Biol. 2014;35: 12299-12304.

[2] Dasararaju R, Marques MB. Adverse effects of transfusion. Cancer Control 2015;22: 16-25.

[3] Garraud O, Cognasse F, Tissot JD, Chavarin P, Laperche S, Morel P, Lefrere JJ, Pozzetto B, Lozano M, Blumberg N, Osselaer JC. Improving platelet transfusion safety: biomedical and technical considerations. Blood Transfus 2016;14: 109-122.

[4] Abel EJ, Linder BJ, Bauman TM, Bauer RM, Thompson RH, Thapa P, Devon ON, Tarrell RF, Frank I, Jarrard DF, Downs TM, Boorjian SA. Perioperative blood transfusion and radical cystectomy: does timing of transfusion affect bladder cancer mortality? Eur Urol 2014;66: 1139-1147.

[5] Linder BJ, Frank I, Cheville JC, Tollefson MK, Thompson RH. The impact of perioperative blood transfusion on cancer recurrence and survival following radical cystectomy. European Urology 2013;63: 839-845.

[6] Moschini M, Bianchi M, Rossi MS, Dell Oglio P, Gandaglia G, Fossati N, Mattei A, Damiano R, Shariat SF, Salonia A, Montorsi F, Briganti A, Colombo R, Gallina A. Timing of blood transfusion and not ABO blood type is associated with survival in patients treated with radical cystectomy for nonmetastatic bladder cancer: Results from a single high-volume institution. Urologic Oncology: Seminars and Original Investigations 2016;34: 256.e7-256.e13.

[7] Shiba H, Ishida Y, Wakiyama S, Iida T, Matsumoto M. Negative impact of blood transfusion on recurrence and prognosis of hepatocellular carcinoma after hepatic resection. Journal of Gastrointestinal Surgery 2009;13: 1636-1642.

[8] Squires RMH, Kooby DA, Poultsides GA, Weber SM, Bloomston M, Fields RC, Pawlik TM, Votanopoulos KI, Schmidt CR, Ejaz A, Acher AW, Worhunsky DJ, Saunders N, Levine EA, Jin LX, Cho CS, Winslow ER, Russell MC, Staley CA, Maithel SK. Effect of Perioperative Transfusion on Recurrence and Survival after Gastric Cancer Resection: A 7-Institution Analysis of 765 Patients from the US Gastric Cancer Collaborative. Journal of the American College of Surgeons 2015;221: 767- 777.

[9] Seicean A, Alan N, Seicean S, Neuhauser D, Selman WR. Risks associated with preoperative anemia and perioperative blood transfusion in open surgery for intracranial aneurysms. J Neurosurg 2015;123: 91-100.

[10] Carling MS, Jeppsson A, Wessberg P, Henriksson A, Baghaei F. Preoperative fibrinogen plasma concentration is associated with perioperative bleeding and transfusion requirements in scoliosis surgery. Spine 2011·36: 549-555.

[11] Foley JH, Conway EM. Cross Talk Pathways Between Coagulation and Inflammation. Circulation Research 2016;118: 1392-1408.

[12] Krychtiuk KA, Kastl SP, Speidl WS, Woita J. Inflammation and coagulation in atherosclerosis. Hmostaseologie 2013;33: 269-280.

[13] Lealnoval SR, Arellano V, Vallejo A, Hernández A, Ez AO. The influence of the preoperative immune response on blood transfusion requirements in patients undergoing cardiac surgery. Journal of Cardiothoracic and Vascular Anesthesia 2009;23: 330-335.

[14] Liu J, Deng X. China anesthesiology guide with expert consensus: Beijing: People's Medical Publishing Press. 2014.

[15] Cata JP, Wang H, Gottumukkala V, Reuben J, Sessler DI. Inflammatory response, immunosuppression, and cancer recurrence after perioperative blood transfusions. Br J Anaesth 2013;110: 690-701.

[16] Liao W, Lin J, Leonard WJ. IL-2 family cytokines: new insights into the complex roles of IL-2 as a broad regulator of T helper cell differentiation. Current Opinion in Immunology 2011;23: 598-604.

[17] Chen K, Kolls JK. Interluekin-17A (IL17A). Gene 2017;614: 8-14.

[18] Kimura A, Kishimoto T. IL-6: Regulator of Treg/Th17 balance. European Journal of Immunology 2010;40: 1830-1835.

[19] Seki N, Miyazaki M, Suzuki W, Hayashi K, Arima K, Myburgh E, Izuhara K, Brombacher F, Kubo M. IL-4-induced GATA-3 expression is a time-restricted instruction switch for Th2 cell differentiation. J Immunol 2004;172: 6158-6166.

[20] Parajuli P, Mittal S. Role of IL-17 in Glioma Progression. Journal of Spine Neurosurgery 2013: S1-004

[21] Kumar R, Kamdar D, Madden L, Hills C, Crooks D, O'Brien D, Greenman J. Th1/Th2 cytokine imbalance in meningioma, anaplastic astrocytoma and glioblastoma multiforme patients. Oncol Rep 2006;15: 1513-1516.

[22] Hu J, Mao Y, Li M, Lu Y. The profile of Th17 subset in glioma. Int Immunopharmacol 2011;11: 1173-1179.

[23] Cantini G, Pisati F, Mastropietro A, Frattini V, Iwakura Y, Finocchiaro G, Pellegatta S. A critical role for regulatory $\mathrm{T}$ cells in driving cytokine profiles of Th17 cells and their modulation of glioma microenvironment. Cancer Immunology, Immunotherapy 2011;60: 1739-1750. 
[24] Fragkou PC, Torrance HD, Pearse RM, Ackland GL, Prowle JR, Owen HC, Hinds CJ, O'Dwyer MJ. Perioperative blood transfusion is associated with a gene transcription profile characteristic of immunosuppression: a prospective cohort study. Crit Care 2014;18: 541.

[25] Torrance HD, Brohi K, Pearse RM, Mein CA, Wozniak E, Prowle JR, Hinds CJ, O'Dwyer MJ. Association Between Gene Expression Biomarkers of Immunosuppression and Blood Transfusion in Severely Injured Polytrauma Patients. Annals of Surgery 2015;261: 751-759.

[26] Maione F, Cicala C, Liverani E, Mascolo N, Perretti M, D Acquisto F. IL-17A increases ADP-induced platelet aggregation. Biochemical and Biophysical Research Communications 2011;408: 658-662.

[27] Hot A, Lenief V, Miossec P. Combination of IL-17 and TNFa induces a pro-inflammatory, pro-coagulant and pro-thrombotic phenotype in human endothelial cells. Annals of the Rheumatic Diseases 2012;71: 768-776.

[28] de Boer OJ, Li X, Teeling P, Mackaay C, Ploegmakers HJ, van der Loos CM, Daemen MJ, de Winter RJ, van der Wal AC. Neutrophils, neutrophil extracellular traps and interleukin-17 associate with the organisation of thrombi in acute myocardial infarction. Thromb Haemost 2013;109: 290-297.

[29] Chiricozzi A, Guttman-Yassky E, Suarez-Farinas M, Nograles KE, Tian S, Cardinale I, Chimenti S, Krueger JG. Integrative responses to IL-17 and TNF-alpha in human keratinocytes account for key inflammatory pathogenic circuits in psoriasis. J Invest Dermatol 2011;131: 677-687.

[30] Griffin GK, Newton G, Tarrio ML, Bu DX, Maganto-Garcia E, Azcutia V, Alcaide P, Grabie N, Luscinskas FW, Croce KJ, Lichtman AH. IL-17 and TNF-alpha sustain neutrophil recruitment during inflammation through synergistic effects on endothelial activation. J Immunol 2012;188: 6287-6299.

[31] Chen T, Qi Z, Jingjun Z, Rong X. Analysis of blood transfusion for patients with brain tumor in perioperative period. Shanghai Medical and Pharmaceutical Journal 2015;36: 7-9. 